Check for updates

Cite this: RSC Adv., 2018, 8, 35461

\title{
Hydroxyethyl substituted linear polyethylenimine for safe and efficient delivery of siRNA therapeutics
}

Received 25th July 2018

Accepted 10th October 2018

DOI: $10.1039 / c 8 r a 06298 f$

rsc.li/rsc-advances

\author{
Sushilkumar Patil, Rohan Lalani, Priyanka Bhatt, Imran Vhora, Vivek Patel, Hinal Patel
} and Ambikanandan Misra (DD *

Linear polyethylenimine (LPEI) has been well reported as a carrier for siRNA delivery. However, its applications are limited due to its highly ionized state at physiologic $\mathrm{pH}$ and the resultant charge mediated toxicity. The presence of ionizable secondary amines in LPE are responsible for its unique characteristics such as $\mathrm{pH}$ dependent solubility and positive charge. Therefore, modification of LPEI was carried out to obtain hydroxyethyl substituted LPEI with the degree of substitution ranging from $15 \%$ to $45 \%$. The impact of modification on the physicochemical parameters of the polymer, i.e. buffer capacity, solubility, biocompatibility and stability, was evaluated. Surprisingly, despite the loss of ionizable amines, the substitution improved solubility, and even overcame the $\mathrm{pH}$ dependent solubility of LPEI. In addition, the conversion of secondary amines to less basic tertiary amines after substitution improved the buffer capacity, in the endosomal $\mathrm{pH}$ range, required for efficient endosomal escape. It also reduced erythrocyte aggregation, hemolytic potential and in vitro cytotoxicity. The in vitro studies showed enhanced cell uptake and mRNA knockdown efficiency. Thus, the proposed modification shows a simple approach to overcome the limitation of LPEI for siRNA delivery.

\section{Introduction}

Antisense-mediated gene inhibition compounds have evolved as a most elegant class of therapeutics. These include small interfering RNA (siRNA), short hairpin RNA (shRNA) and bifunctional shRNA. The progress made in human genome mapping and an improved understanding of signal transduction have broadened their application horizon. It takes a powerful molecular process to modulate gene expression by inducing the endogenous RNAi machinery to direct mRNA degradation. ${ }^{1}$ Notably, siRNA provides the advantages of a wide choice of targets, easy synthesis, extended period of target suppression, high target selectivity over non-targets giving a better therapeutic index and significantly improved quality of therapy compared to small molecule inhibitors. ${ }^{2}$

However, in spite of showing tremendous therapeutic potential, RNAi-based therapeutics are far from clinical usability. The first clinical trial was started in 2004 and many more thereafter, however, majority of these trials, with few exceptions, could last for phase I or early phase II stages only. ${ }^{3} \mathrm{~A}$ key challenge for their successful clinical application is the efficient and safe delivery of siRNA into target cells against milieu of extracellular and intracellular barriers. The extracellular barrier includes hydrolytic instability, nuclease degradation; hydrophilicity and negative charge restricting its

Faculty of Pharmacy, The Maharaja Sayajirao University of Baroda, Kalabhavan Campus, Vadodara-390001, Gujarat, India.E-mail: misraan@hotmail.com cytoplasmic entry by diffusion. Further, the intracellular barriers such as endosomal degradation and intracellular trafficking also co-exist to preclude easy entry. ${ }^{2}$ A potential solution to overcome these problem has been provided by viral/non-viral gene delivery vectors.

Non-viral vectors are safe and less immunogenic than viral vectors. Further, non-viral vectors composed of cationic polymers are preferred over lipid based carrier when greater stability is desired in physiological environment. ${ }^{4}$ Cationic polymers contain several amine groups in their backbone which interact with negatively charged siRNA leading to spontaneous formation of nanosized complexes. Among these cationic polymers, PEI, especially branched PEI (bPEI), is well-known as good transfection reagent due to its intrinsic proton sponge property. ${ }^{5}$ However, due to high toxicity and lack of biodegradability, it has no clinical applications. In contrast, linear PEI (LPEI) is less toxic but it displays low transfection capacity. ${ }^{6}$

The high transfection efficiency of bPEI has been attributed to the unique ratio of $1^{\circ}: 2^{\circ}: 3^{\circ}$ amines of $1: 2: 1$ imparting it a typical ionization behavior. However, LPEI, being composed of only secondary amines, fails to behave similar to bPEI, as most of amines get protonated in $\mathrm{pH}$ range of 8.2 to $9.5 .^{7,8}$ Several modifications of LPEI have been tried for improved transfection efficiency, however most of them involved tedious and multistep synthesis. ${ }^{6-9-13}$ Therefore, we attempted a simple modification of LPEI to influence its ionization behavior, hydrophilicity and consequently the biological properties such as cell uptake and transfection efficiency. 


\section{Experimental}

\subsection{Materials}

LPEI (22 kDa), was gift from polychemistry, USA. Lipofectamine ${ }^{\circledR} 2000$ (L2K) was purchased from Invitrogen Life Technologies (New York, USA). 2-Bromoethanol was purchased from Sigma Aldrich, Bangalore. siRNA targeting human epithelial sodium channel (ENaC) with antisense strand sequence of $\left(5^{\prime} \rightarrow 3^{\prime}\right)$ ACUCCAACCUCUGGAUGAC was purchased from Eurofins MWG Operons Ltd (Germany). Carboxyfluorescene FAM labelled negative control siRNA (FAM-NCsiRNA) and non-target control siRNA (NTC control) with antisense strand sequence $\left(5^{\prime} \rightarrow 3^{\prime}\right)$ ACGUGACACGUUCGGAGAA was gift sample from GenePharma (Shanghai, China). The cell culture reagents such as: 4',6-diamidino-2-phenylindole (DAPI), 3-(4,5-dimethylthiazol-2-yl)-2,5-diphenyl tetrazolium bromide, Eagle's minimal essential medium (EMEM), Fetal bovine serum (FBS), Antibiotic antimycotic solution $(100 \times)$ were purchased from Himedia (Mumbai, India).

\subsection{Preparation of LPEI}

LPEI was modified to achieve different degrees of substitution (DS) on LPEI backbone to obtain hydroxyethyl substituted LPEI (HELPEI). Briefly, $500 \mathrm{mg}$ of LPEI was dissolved in ethanol in a round bottom flask. 2-Bromoethanol was added to it at varying molar ratios to amine content in LPEI. Then $3.2 \mathrm{~g}$ potassium carbonate was added as proton abstractor. The RBF was placed on a preheated oil bath and refluxed for $48 \mathrm{~h}$ and increamental quantity of $1.6 \mathrm{~g} \mathrm{~K} \mathrm{~K}_{2} \mathrm{CO}_{3}$ was added at 12 and $24 \mathrm{~h}$. After completion the reaction mixture was centrifuged and supernatant was collected and evaporated under vacuum (400 $\mathrm{mmHg}$ ) on rotary evaporator at room temperature. The residue obtained was reconstituted in double distilled water and dialyzed against double distilled water to remove salts and any other low molecular impurities. The retentate of the dialysis were lyophilized to obtain dry residue of HELPEI.

\subsection{Characterization}

For structural characterization, ${ }^{1} \mathrm{H}$ NMR spectra of HELPEI were recorded on Bruker Avance II 400 NMR spectrometer at 400 MHz. For this, LPEI and HELPEI were dissolved in $\mathrm{D}_{2} \mathrm{O}$ and ${ }^{1} \mathrm{H}$ NMR spectroscopy was performed with a $5 \mathrm{~mm}$ probe. All the reactions were set at mole to mole basis to get desired DS, and it was confirmed by ${ }^{1} \mathrm{H}$ NMR. The degree of substitution (DS) was determined by peak integration using the following relation:

$$
N=\frac{\text { Peak area of } \mathrm{C}_{2} \mathrm{H}_{4} \text { in hydroxyethyl } \times 100}{\text { peak area of } \mathrm{C}_{2} \mathrm{H}_{4} \mathrm{~N}_{2} \text { in PEI }}
$$

The peak integration at chemical shifts of $\delta 2.3$ to 2.9 were considered for $\mathrm{C}_{2} \mathrm{H}_{4}$ in ethylene backbone, and $\delta 3.25$ to 3.61 for $\mathrm{C}_{2} \mathrm{H}_{4}$ in hydroxyethyl substituent.

Further, the effect of substitution on solubility of HELPEI was evaluated. Briefly, PEI were dissolved in $0.1 \mathrm{~N} \mathrm{HCl}(1 \mathrm{mg}$ $\mathrm{mL}^{-1}$ ), the $\mathrm{pH}$ of solution was titrated from 5.0 to 12.0 by using $0.1 \mathrm{M} \mathrm{NaOH}$ solution. The transmittance of solution at $600 \mathrm{~nm}$ as a function of $\mathrm{pH}$ value was recorded on a UV-visible spectrophotometer (Shimadzu, Japan).

\subsection{Proton sponge effect}

The buffer capacity of the LPEI and HELPEI from pH 10 to 3.5 was determined by acid-base titration as reported in literature. ${ }^{14}$ Briefly, $10 \mathrm{mg}$ of polymer was dissolved in $150 \mathrm{mM} \mathrm{NaCl}$ solution. The solutions were adjusted to an initial $\mathrm{pH}$ of 10.0 using $1 \mathrm{~N} \mathrm{NaOH}$ and then titrated with $0.1 \mathrm{~N} \mathrm{HCl}$ and $\mathrm{pH}$ was recorded using a $\mathrm{pH}$ meter. Buffer capacity was defined as the percentage of amine groups protonated from $\mathrm{pH} 7.4$ to 5.1, and was calculated using following equation:

$$
\text { Buffer capacity }(\%)=\frac{\Delta V \times 0.1 \mathrm{M} \times 100}{N \mathrm{~mol}}
$$

wherein, $\Delta V$ is the volume of $\mathrm{HCl}$ required to bring the $\mathrm{pH}$ from 7.4 to 5.1 , and $N$ mol is total moles of protonable amines in given amount of polymer. ${ }^{15}$ Additionally, the ratio of protons consumed in intervals of 7.4-5.1 to $10-7.4$ was calculated as secondary indicator of effect of DS on basicity of amines.

\subsection{Preparation of polyplex}

Since complexation efficiency of LPEI is function of charge density and $\mathrm{pH}$, all the polyplex were prepared in nuclease free water adjusted to $7.4 \mathrm{pH}$ using $20 \mathrm{mM}$ sodium acetate. The required amount of polymer stock solution $\left(10 \mathrm{mg} \mathrm{mL}^{-1}\right)$ was diluted with sodium acetate buffer and then mixed with siRNA at varying $\mathrm{n} / \mathrm{p}$ ratio. The mixture was gently vortexed for $2 \mathrm{~min}$ and incubated for $40 \mathrm{~min}$ at $25{ }^{\circ} \mathrm{C}$.

\subsection{Gel retardation assay}

Agarose gel electrophoresis was used to study the complexation of LPEI and HELPEI with siRNA at different $\mathrm{n} / \mathrm{p}$ ratio. Briefly, all the incubated polyplexes $(20 \mu \mathrm{L})$ were mixed with $6 \times$ DNA gel loading buffer (Himedia, India) and loaded onto $4 \%$ agarose gel containing $0.5 \mu \mathrm{g} \mathrm{mL}{ }^{-1}$ ethidium bromide and electrophoresed at $50 \mathrm{~V}$ in Tris-borate EDTA buffer pH adjusted to 7.4. Electrophoresed gel was visualized under UV trans-illuminator using Gel Doc System (Bio-Rad Lab., USA). The n/p ratio required for complete retardation of siRNA were determined for each polymer. The complexation efficiency was determined by centrifugal assay previously reported. ${ }^{\mathbf{1 6}, 17}$ Briefly, siRNA polyplexes were centrifuged at $25000 \mathrm{rpm}$ for $45 \mathrm{~min}$ at $4{ }^{\circ} \mathrm{C}$. The aqueous supernatant after centrifugation was separated and analyzed for siRNA content using NanoDrop UV spectrophotometer (Thermo scientific, USA).

\subsection{Size and zeta potential}

The hydrodynamic size of the polyplexes was determined by using dynamic light scattering using Zetasizer, Nano ZS series (Malvern Instruments, Germany). The prepared polyplexes were diluted appropriately with nuclease free water $\mathrm{pH} 7.4$ and measurements made at $25{ }^{\circ} \mathrm{C}$. Similarly zeta potential was measured by applying Smoluchowski's equation in the zeta sizer software. 


\subsection{Biocompatibility assessment}

2.8.1. Erythrocytes aggregation assay. Cationic polymers are known to induce erythrocyte aggregation; therefore, erythrocyte aggregation was used to evaluate biocompatibility of polymers. Erythrocytes were isolated from a fresh heparinized rat blood by centrifugation at $1000 \mathrm{~g}$ for $10 \mathrm{~min}$ at $4{ }^{\circ} \mathrm{C}$. The obtained pellet was washed several times with PBS pH 7.4 until the supernatant became clear. Finally, the erythrocytes were reconstituted in PBS pH 7.4 to prepare $2 \% \mathrm{v} / \mathrm{v}$ suspension. 500 $\mu \mathrm{L}$ of $2 \%$ erythrocyte suspension containing $50 \mu \mathrm{g} \mathrm{mL} \mathrm{m}^{-1}$ polymer were prepared in PBS pH 7.4 mixed thoroughly by vortexing and incubated for $2 \mathrm{~h}$ at $37^{\circ} \mathrm{C}$. The erythrocyte aggregation was visualized using Nikon Eclipse TS100 inverted microscope (Nikon, Japan) in phase contrast mode.

2.8.2. Hemolysis study. For hemolysis, $500 \mu \mathrm{L}$ of $2 \%$ erythrocyte suspension containing 10, 100, 1000, $2000 \mu \mathrm{g} \mathrm{mL}$ polymer were prepared and thoroughly mixed by vortex and incubated at $37{ }^{\circ} \mathrm{C}$ for $1 \mathrm{~h} .{ }^{18}$ After incubation, cell suspension was centrifuged at $3000 \mathrm{rpm}$ for $10 \mathrm{~min}$ and the supernatant was analyzed for hemoglobin release through absorbance measurement at $540 \mathrm{~nm}$. PBS and 1\% Triton X 100 was used as negative and positive control respectively. There was no interference of polymer at $540 \mathrm{~nm} .{ }^{19}$ The $\%$ hemolysis was calculated using the formula:

$$
\text { Haemolysis }=\frac{A_{\mathrm{s}}-A_{\mathrm{n}}}{A_{\mathrm{s}}-A_{\mathrm{n}}} \times 100
$$

where, $A_{\mathrm{s}}$ is the absorbance of supernatant, $A_{\mathrm{n}}$ and $A_{\mathrm{p}}$ is the absorbance of negative and positive control, respectively.

2.8.3. Cytotoxicity of polymer. Human bronchial epithelial cells (CFBE410-) were kind gift from Dr Dieter Gruenert (California Pacific Medical Center Research Institute and Department of Laboratory Medicine, University of California, San Francisco CA). The cells were seeded in a 96 well plate (5000 cells per well) in EMEM with $10 \%$ FBS and incubated at $37{ }^{\circ} \mathrm{C}$ with $5 \% \mathrm{CO}_{2}$ in humidified conditions for $24 \mathrm{~h}^{20}$ After confluency, cells were exposed to polymers at concentrations of 5 , 10, 20, 40, $80 \mu \mathrm{g} \mathrm{mL}{ }^{-1}$ in EMEM for $6 \mathrm{~h}$. Then, cells were washed with PBS and incubated for $24 \mathrm{~h}$ in fresh EMEM with $10 \%$ FBS and 1\% antibiotic. After incubation, media was removed and cells were washed with PBS and $20 \mu \mathrm{L}$ of MTT solution $\left(5 \mathrm{mg} \mathrm{mL}^{-1}\right.$ ) was added to each well and further incubated for $4 \mathrm{~h}$. Then medium was removed and $100 \mu \mathrm{L}$ of dimethyl sulfoxide was added to dissolve the formazan crystals. The plates were subjected to colorimetric analysis at $570 \mathrm{~nm}$ in a microtiter plate reader (Biorad, California) to determine amount of dissolved formazan. Cells were treated with EMEM (negative control) and $0.2 \%$ Triton $\mathrm{X}$ (positive control) and cell viability was expressed relative to negative control.

\subsection{Stability challenge studies}

2.9.1. Salt induced aggregation. To assess the stabilizing effect of hydroxyethyl substitution against salt, polyplexes were prepared at $100 \mathrm{nM}$ siRNA concentration. Accurately weighted quantities of $\mathrm{NaCl}$ were mixed to obtain concentration of $1 \%$,
$2 \%, 3 \%, 4 \%, 5 \% \mathrm{w} / \mathrm{v} \mathrm{NaCl}$ and particle size of each formulation was measured using dynamic light scattering after each addition.

2.9.2. Heparin displacement assay. The extracellular matrix is replete with polyanionic glycosaminoglycan which may interact with the cationic carriers leading to displacement of siRNA. The polyplexes prepared at optimized $n / p$ ratio were exposed to increasing heparin concentrations and polyplex dissociation was observed by gel electrophoresis. In each case, the heparin/siRNA ratio necessary to displace siRNA from polyplex was noted.

2.9.3. Serum stability study. Serum stability was performed to study stability under simulated in vivo conditions. The optimized polyplexes were incubated with $50 \%$ FBS at $37{ }^{\circ} \mathrm{C}$. After incubation, integrity of siRNA was analyzed in the samples through gel electrophoresis at different time intervals. Briefly, EDTA $(0.5 \mathrm{M})$ was added to samples at each time point to inhibit any nuclease activity and the polyplexes were treated with $1 \mathrm{mg}$ $\mathrm{mL}^{-1}$ heparin so as to dissociate the polyplexes. Thus, released siRNA were electrophoresed on gel and compared for integrity with the untreated siRNA sample. The siRNA retained by polyplexes at different time intervals was quantified using densitometry.

\subsection{Transmission electron microscopy (TEM)}

TEM was performed to study the morphology of particles. Briefly, a sample drop was placed onto 300 \# carbon coated copper grid. Using filter paper, the surface water from the grid was removed by tapping. After $5 \mathrm{~min}$, grid was inserted into microscope using a sample probe and observed at $200 \mathrm{kV}$ accelerating voltage with suitable magnification $(25 \times$ to $75000 \times)$.

\subsection{Cell uptake}

2.11.1. Confocal microscopy. CFBE410- cells were seeded in a 24 well plate $\left(10^{4}\right.$ cells per well) over a flame sterilized cover glass ( $0.17 \mathrm{~mm}$ thick). After $24 \mathrm{~h}$ incubation, cells were exposed to optimized siRNA polyplexes of FAM-NC-siRNA at siRNA concentration of 100 mM. FAM-NC-siRNA/ Lipofectamine 2000 (L2K) complexes, as positive control, were prepared as per Invitrogen protocol. After $6 \mathrm{~h}$ of treatment, cells were washed twice with PBS and fixed with $4 \%$ paraformaldehyde solution ( $1 \mathrm{~mL}$ per well) by incubation for 3-5 min followed by immediate wash of PBS thrice. DAPI solution $\left(1 \mu \mathrm{g} \mathrm{mL}^{-1}\right)$ was used to stain the nuclei for $15 \mathrm{~min}$ at room temperature followed by PBS wash. The PBS : glycerin solution (50:50) was used for mounting coverslips and confocal microscopy was performed using confocal microscope (LSM 710, Carl-Zeiss Inc., USA).

2.11.2. FACS. CFBE410- cells were seeded in 24 well plate ( 5 $\times 10^{5}$ cells per well) and incubated at $37{ }^{\circ} \mathrm{C}$ with $5 \% \mathrm{CO}_{2}$ in humidified conditions for $24 \mathrm{~h}$. After confluency, cells were treated and kept at $37{ }^{\circ} \mathrm{C}$ for $6 \mathrm{~h}$ with FAM-NC-siRNA complex formulations at a concentration of $100 \mathrm{nM}$. After incubation cells were washed thrice with cold PBS pH 7.4 and harvested using trypsin to obtain a cell suspension in PBS $\mathrm{pH} 7.4$, and 
analyzed using FACS-BD-Aria III BD, UDA. Naked FAM-NCsiRNA and L2K complexed siRNA were used as negative and positive control, respectively. FlowJo software, version 10 was used to analyze the data obtained from flow cytometer.

\subsection{In vitro gene silencing}

In a 24 well plate, CFBE410- cells were seeded $\left(10^{5}\right.$ cells per well) and incubated for $24 \mathrm{~h}$. After $80 \%$ confluency, cells were treated at three different concentrations of $\mathrm{ENaC} \alpha$ siRNA i.e. $25 \mathrm{nM}$, $50 \mathrm{nM}$ and $100 \mathrm{nM}$ prepared as polyplex formulations. Untreated cells were used as negative control while L2K was used as positive control. The gene expression was reported relative to untreated control. NC-siRNA as HELPEI-35-siRNA polyplexes was used to confirm the specificity. After incubation for $48 \mathrm{~h}$, total RNA was isolated using TRIzol reagent and reverse transcription into cDNA was carried out using RNA to cDNA conversion kit. mRNA level was quantified using Step One Real Time PCR using SYBR Green Mastermix, forward and reverse primers (primers for $\mathrm{ENaC} \alpha$ : $\mathrm{F}-5^{\prime}$-CCTGGAATCAACAACGGTCT, R-5'-AGGGTTTCCTTCCTCATGCT producing PCR product of $188 \mathrm{bp}$; primers for GAPDH: F-5'-ATCCCATCACCATCTTCCAGG, R-5'-CAAATGAGCCCCAGCCTTCT producing PCR product of $122 \mathrm{bp}$ ) and $2 \mathrm{ng}$ of cDNA in a total reaction volume of $15 \mu \mathrm{L}$. The mRNA expression was normalized against housekeeping gene glyceraldehyde-3-phosphate dehydrogenase (GAPDH).

\subsection{Statistical analysis}

Experiments were performed in triplicate and data are expressed as the mean \pm standard deviation (SD), unless otherwise stated. The statistical significance testing was performed using a Student's $t$-test with $p<0.05$.

\section{Result and discussion}

\subsection{Characterization}

The structural modification led to changes in chemical shifts values of proton. ${ }^{1} \mathrm{H}$ NMR spectrum showed that in case of LPEI, protons of $\mathrm{C}_{2} \mathrm{H}_{4}$ in ethylene backbone showed peaks at chemical shift $(\delta)$ values of 2.3 to 2.9 while the protons of $\mathrm{C}_{2} \mathrm{H}_{4}$ in hydroxyethyl substituent show downfield shift in range of $\delta 3.25$ to 3.61 due to de-shielding effect of -OH group (Fig. 1). Based on the chemical shift, integrations were performed in the scanned NMR spectra of HELPEIs and DS was determined as shown in Table 1.

Further, modification of LPEI led to significant effects on solubility of the polymer. LPEI is insoluble in water at temperatures below $55{ }^{\circ} \mathrm{C}$, with resultant $\mathrm{pH}$ of around 9.2. The $\mathrm{pH}$ solubility profile of LPEI and HELPEI was studied from pH 6.0 to 11.0 at room temperature. Fig. $2 \mathrm{~A}$ and B shows the results of solubility studies using turbidimetry. The transmittance values at $600 \mathrm{~nm}$ showed that, at $\mathrm{pH}$ above 8.0 there is tremendous drops in transmittance of LPEI from $>90 \%$ to less than $20 \%$. LPEI becomes insoluble when it is less than $20 \%$ protonated, which occurs at $\mathrm{pH}$ values $>9.0$. Surprisingly, despite of loss of ionisable amines due to substitution, all HELPEIs with DS of $25 \%$ and above showed $>94 \%$ transmittance at all $\mathrm{pH}$ values. This indicates that hydroxyethyl substitution is also capable of introducing hydrophilicity to HELPEIs and overcomes the $\mathrm{pH}$ dependent solubility, due to which even at $\mathrm{pH}>9.0$ where amines are un-ionized, HELPEIs remain soluble.
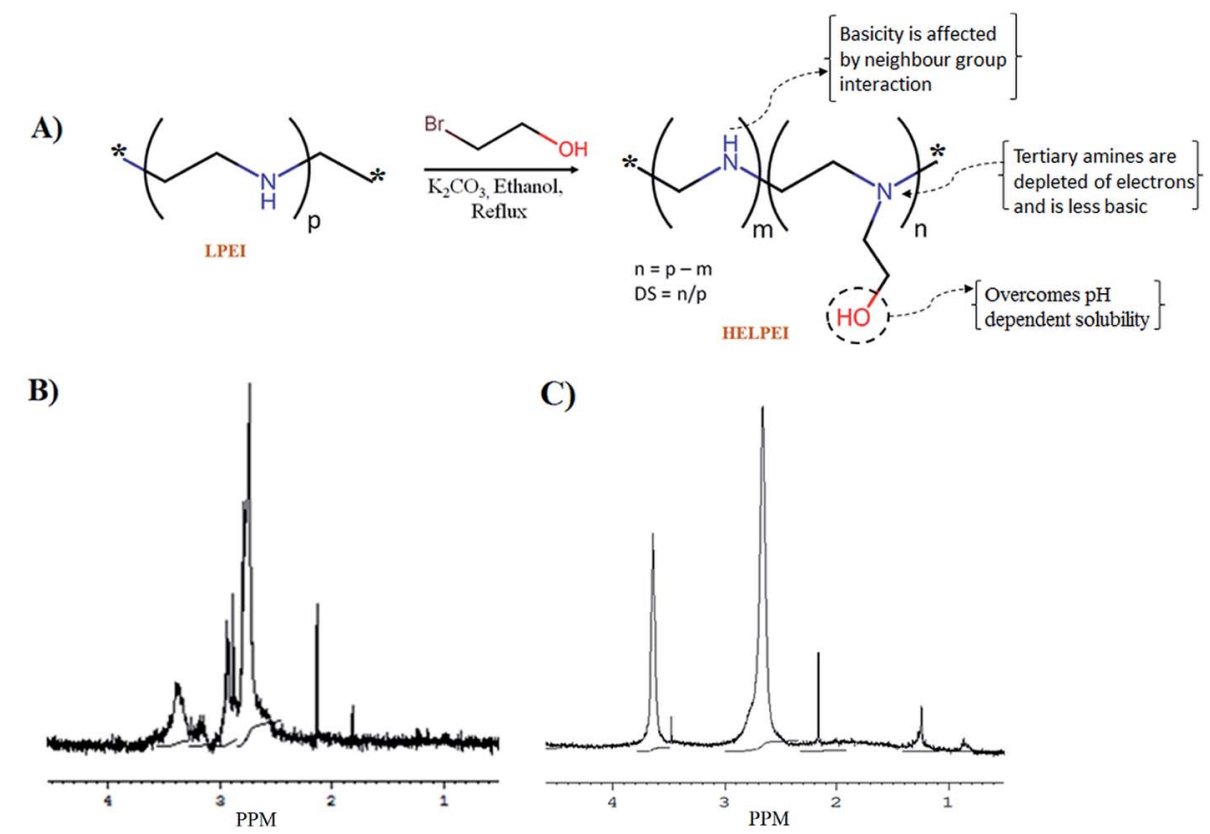

Fig. 1 (A) General scheme for preparation of HELPEls with illustration of hypothesis (B) ${ }^{1} \mathrm{H}$ NMR spectrum of $L P E l$; (C) ${ }^{1} \mathrm{H}$ NMR spectrum of HELPEI-45. 
Table 1 Summary of polymer characteristics

\begin{tabular}{|c|c|c|c|c|}
\hline Polymer & Actual DS & Molecular weight (Da) & Ratio of $\mathrm{HCl}^{a}$ & Buffering capacity (\%) \\
\hline LPEI & 0 & 22000 & $0.31 \pm 0.022$ & $10.32 \pm 0.22$ \\
\hline HELPEI-15 & 11.75 & 24645 & $0.34 \pm 0.018$ & $13.53 \pm 0.35$ \\
\hline HELPEI-35 & 33.38 & 29514 & $0.44 \pm 0.038$ & $17.31 \pm 0.34$ \\
\hline HELPEI-45 & 43.26 & 31738 & $0.50 \pm 0.028$ & $18.28 \pm 0.27$ \\
\hline bPEI-25 kDa & - & - & $0.38 \pm 0.034$ & $17.85 \pm 0.25$ \\
\hline
\end{tabular}

\subsection{Proton sponge effect}

Buffer capacity is one of the most essential traits sought in a gene vector, which plays role in destabilization of endosome and releases the polyplexes from endosomes. Previous studies with PEGylated PEI reported that grafting of PEG to PEI have resulted in reduction in buffer capacity due to shielding effect of PEG. ${ }^{21}$ The pKa of LPEI is influenced by presence of salt due to screening of electrostatic potential around LPEI chain (shifting of $\mathrm{p} K_{\mathrm{a}}$ to higher values), therefore titrations were performed in $150 \mathrm{mM} \mathrm{NaCl}$ solution.

The secondary amines of LPEI are basic in nature with $\mathrm{p} K_{\mathrm{a}}$ in range of 9.0. Hydroxyethyl substitution could lead to significant deviation in protonation behavior. It converts secondary amines to tertiary amines, which are depleted of electron density and thereby have reduced basicity. The order of basicity of amines in aqueous media is as follows: primary amine $>$ secondary amine
$>$ tertiary amine. In addition, all the secondary amines of LPEI are not protonated at same $\mathrm{pH}$, as titratable sites are close together, i.e. only two methylene units separating nitrogen, protonation state of a site electrostatically affects the protonation of nearby sites. The analogy can be made from ethylenediamine, which requires a significantly lower $\mathrm{pH}\left(\mathrm{p} K_{2}\right.$ of 7.08) for protonation of second amine to occur after the first amine group ( $\mathrm{p} K_{1}$ of 9.89) has been protonated. Finally, as chain becomes increasingly substituted, the next-nearest-neighbor interactions leads to further deviation in protonation behavior. ${ }^{8}$

To assess the quantitative effect of modification of LPEI on protonation behavior, the titration curve was divided into different regions. The region 10 to 7.4 indicates the approximate amount of protonated amines at physiologic pH. Fig. 2 shows that LPEI curve was inclined in this region and therefore becomes most cationic at physiologic $\mathrm{pH}$. While all HELPEIs curves were steep in this region due to reduced protonation in
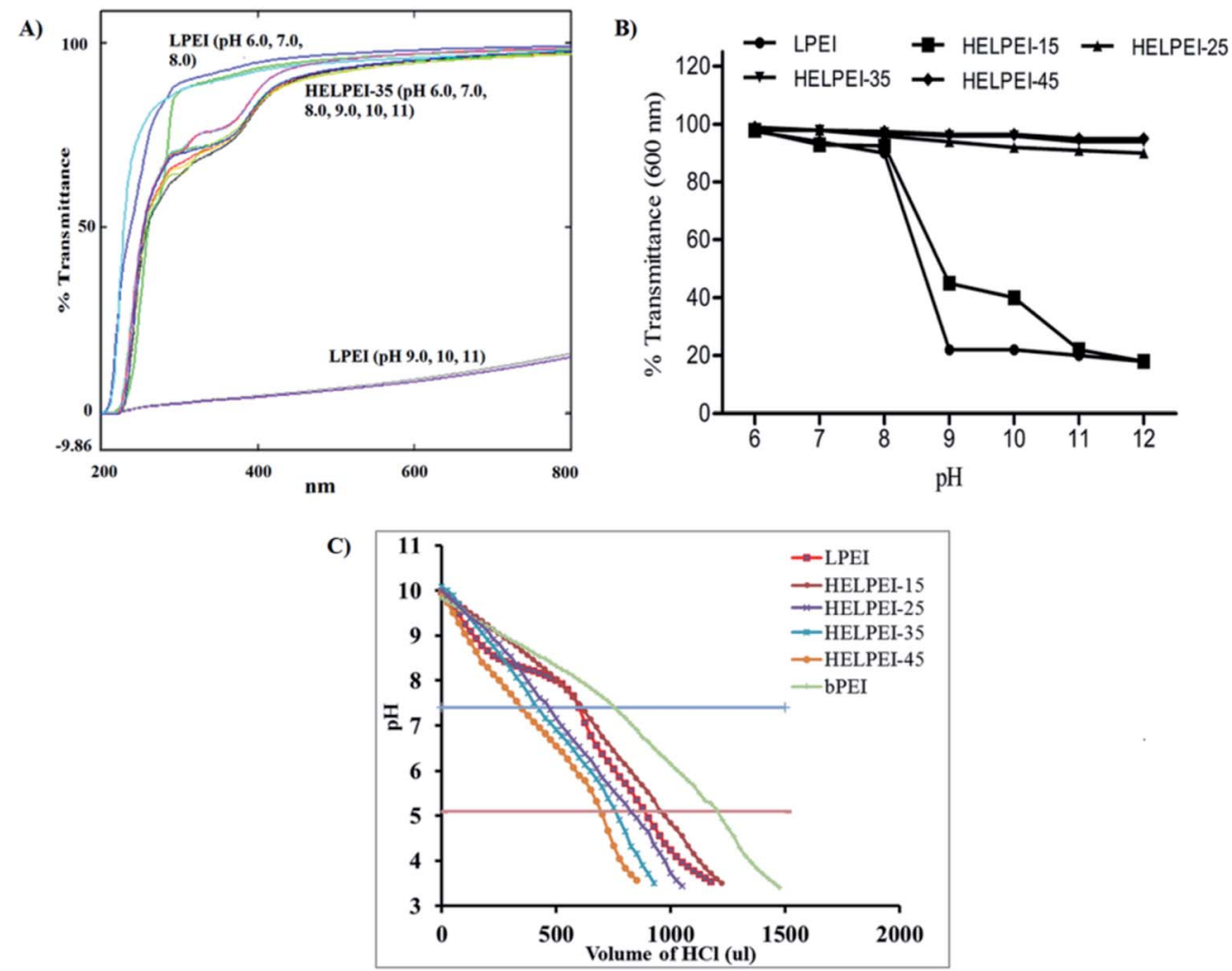

Fig. 2 (A) Overlay of UV-transmittance spectra of LPEI, at pH 6, 7, 8 (top three), and pH 9.0 to 11 (at bottom) and HELPEI-35, at pH 6.0 to 11. (B) Summary plot of transmittance of LPEI and HELPEI at different $\mathrm{pH}$. (C) Acid-base titration of LEPI and HELPEI with $0.1 \mathrm{~N} \mathrm{HCl}$. 
this region. Further, the comparison of ratio of protons consumed in $\mathrm{pH}$ range of 7.4-5.1 (endosomal $\mathrm{pH}$ ) to the protons consumed in $\mathrm{pH}$ range of 10-7.4, showed an increasing trend with increasing DS. Finally, the buffer capacity calculations (Table 1) show that, the buffer capacity of LPEI was lowest i.e. 10.32, which increased with increasing DS and it crossed buffer capacity of bPEI (the standard used in proton sponge assays).

\subsection{Gel retardation assay}

For LPEI the optimized n/p ratio for complete retardation was 4 . This is because, LPEI being at least $55 \%$ of the amines protonated at $7.4 \mathrm{pH}$, leads to strong electrostatic interaction. ${ }^{22}$ The $\mathrm{n} / \mathrm{p}$ ratio for complete retardation for HELPEI-15, HELPEI25, HELPEI-35, and HELPEI-45 were 5, 6, 8, and 15, respectively (Fig. 3). This implies that with increase in DS the binding affinity of HELPEI to siRNA is reduced. The effect could be attributed to suppression of ionization and reduced charge density. Literature has reported that after substitution with PEG molecules there is a drastic reduction in binding efficiency due to shielding of charges. ${ }^{23,24}$ This may eventually lead to higher intake of non-biodegradable polymer to deliver the desired dose of siRNA. In contrast, the substitution with low molecular weight hydroxylethyl group could be advantageous as it does not lead to such drastic reduction in binding affinity.

However, as the DS is increased from $35 \%$ to $45 \%$ there was an anomalous increase in $\mathrm{n} / \mathrm{p}$ required for complete retardation. This indicates that the charge reduction was non linear with DS beyond certain point. This deviation could be attributed to the fact as chain becomes increasingly susbtituted, the cumulative build-up of neighbour interactions leads to significant supression of basicity of nitrogens. ${ }^{8}$ Thus to deliver same dose of siRNA, higher quantity HELPEI-45 would be required.

\subsection{Size and zeta potential}

The size of polyplexes formed from HELPEIs with lower DS were comparatively smaller than with higher DS at the given $n / p$ ratio, showing that there is decrease in the affinity of polymer
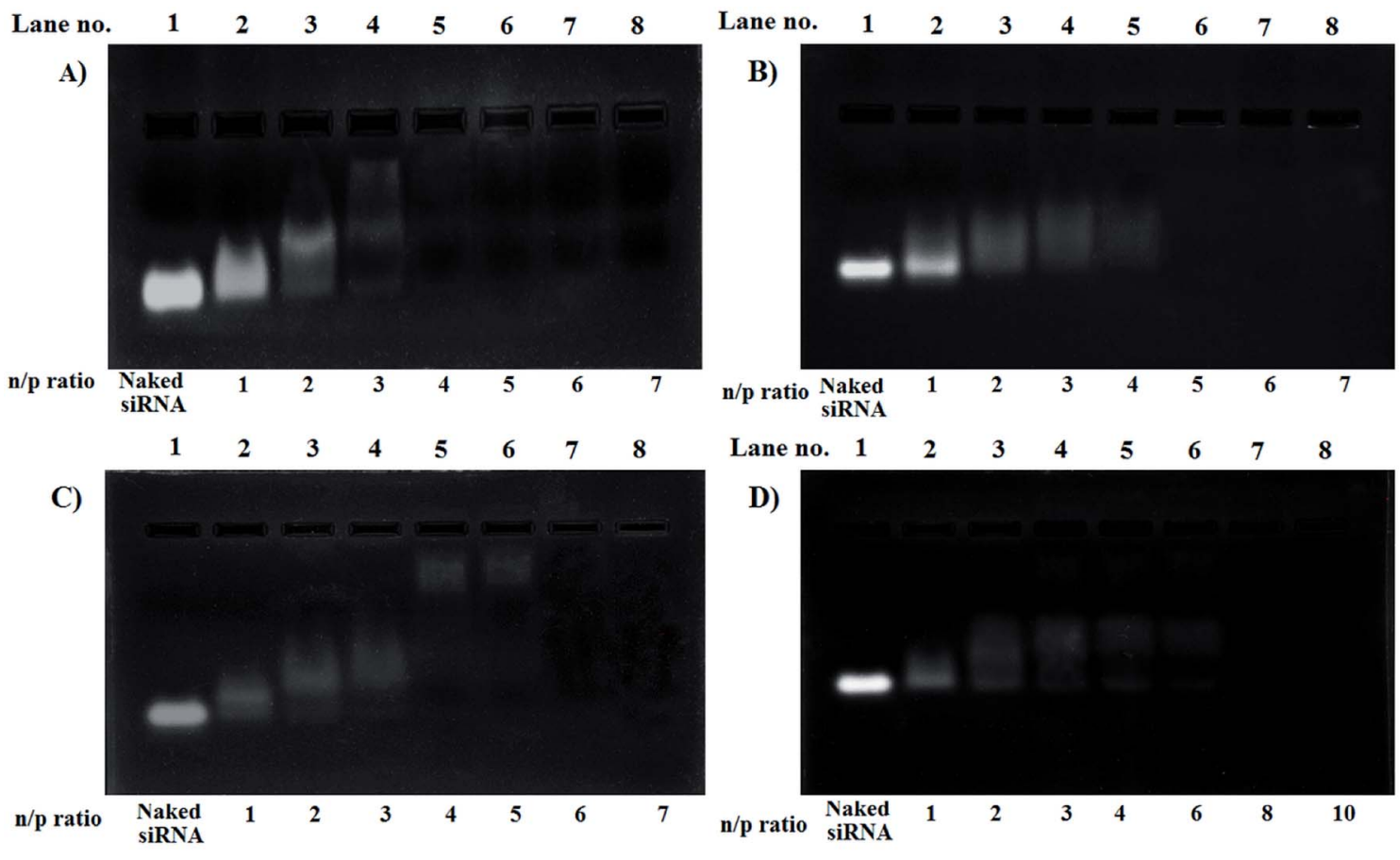

D)
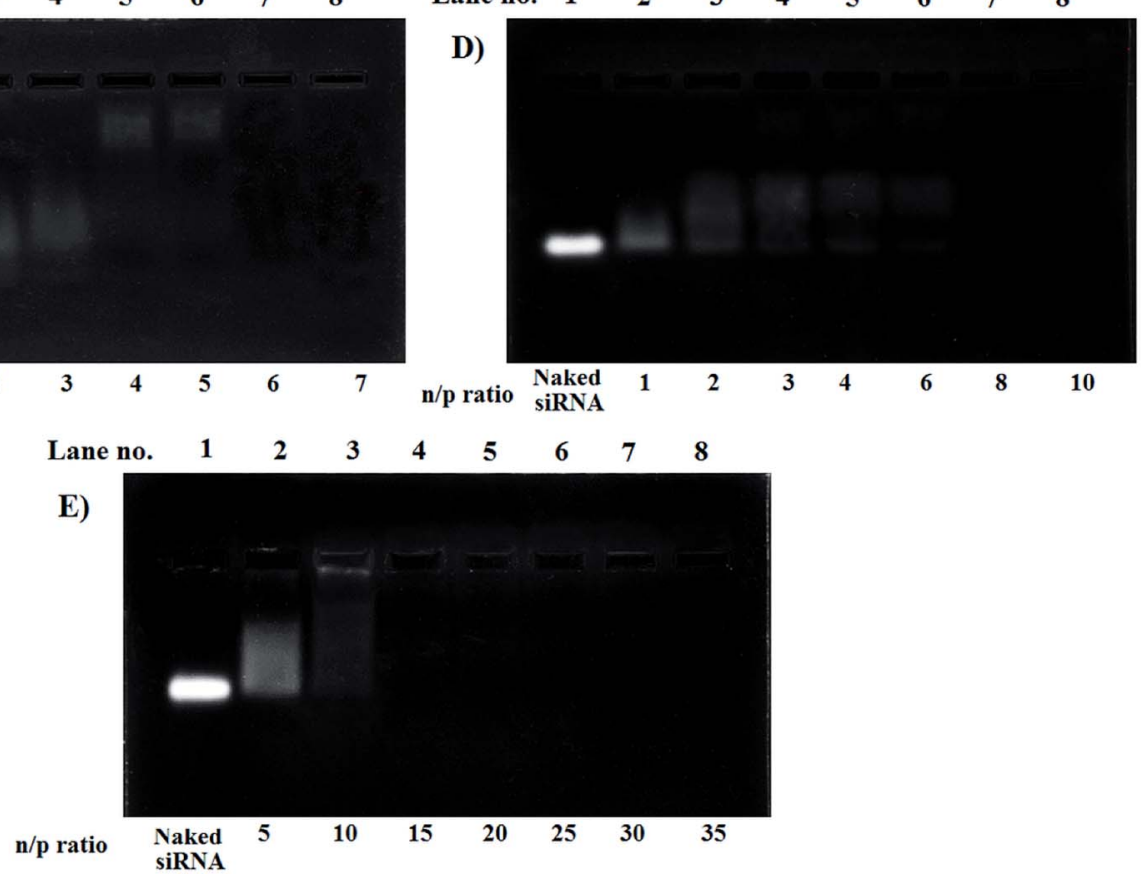

Fig. 3 Gel electrophoresis images for gel retardation assay of polyplexes of (A) LPEI, (B) HELPEI-15, (C) HELPEI-25, (D) HELPEI-35 and (E) HELPEI45. 
with higher DS. However, as the $\mathrm{n} / \mathrm{p}$ was increased the sizes for all were $<200 \mathrm{~nm}$, as desired. The results of zeta potential showed that polyplexes were able to maintain the positive charge after complexation with anionic siRNA molecules. However, as DS increased the zeta potential was found to decrease. The decrease in zeta potential could be the result of reduced ionization of the amines on the polymeric backbone at measurement $\mathrm{pH}$ of 7.4. As expected the increase in $\mathrm{n} / \mathrm{p}$ values led to increase in zeta potential. The effect of $n / p$ ratio on particle size, PDI and zeta potential is shown in Table 2 .

\subsection{Complexation efficiency}

The amount of siRNA in free form is prone to degradation by nucleases and hydrolytic conditions present in extracellular milieu. ${ }^{25}$ Therefore, it was necessary that the optimized $\mathrm{n} / \mathrm{p}$ ratio contains maximum amount of siRNA in bound form to the vector. The polyplexes were characterized for complexation efficiency by centrifugal assay. Table 3 shows that both the LPEI and HELPEIs were able to condense more than 95\% of siRNA at their optimized $\mathrm{n} / \mathrm{p}$ ratios.

\subsection{Biocompatibility study}

3.6.1. Hemolysis. During hemolysis, polymers produce nano-sized pores in cell membrane inducing an influx of solutes into the cells which causes rupture by destabilization of membrane and release of hemoglobin molecules. Along with charge, polymer structure and conformation has also been implicated in toxicity, wherein rigid and helical conformations are said to be more membrane permeabilizing. ${ }^{26}$ Fig. 4, shows that LPEI caused extensive hemolysis $(>10 \%)$ at concentration ranging from 10 to $2000 \mu \mathrm{g} \mathrm{mL}^{-1}$ (Fig. 4B). As stated earlier, LPEI is more than $50 \%$ ionized at $\mathrm{pH} 7.4$ leading to charge dependent toxicity. ${ }^{8}$ Surprisingly, bPEI exhibited less hemolysis compared to LPEI at all concentrations. This could be because of bPEI being comparatively less ionized at $\mathrm{pH} 7.4$, as only $25 \%$ of total amine content is primary amine and $50 \%$ is of secondary amine which are partially ionized. ${ }^{27}$ However, HELPEI-15 to HELPEI-45 led to significant decrease in hemolysis $(p<0.05)$. Noticeably, HELPEI35 and HELPEI-45 showed $<3 \%$ hemolysis at all the concentrations. This can be attributed to combined effect of increase in hydrophilicity and the decrease in charge density. Besides charge reduction, the substitution may make polymer flexible, affecting the conformation responsible for membrane adsorption and permeabilization. ${ }^{28}$

3.6.2. Erythrocyte aggregation. During aggregation process the polymer molecules first interact with the surface of colloids and then bridge/chains inter-tangle with each other leading to flocculation and aggregation. ${ }^{29}$ As shown in Fig. 4A, it was observed that LPEI induced significant erythrocyte aggregation at all the concentrations selected. However, in case of HELPEIs the erythrocyte aggregation was found to be reduced with increase in DS. The HELPEI-15 and HELPEI-25 showed aggregation as that of LPEI indicating that the cationic charge present even after $25 \%$ DS was sufficient to interact with cell membrane and induce aggregation. When DS reached $35 \%$ and $45 \%$ the resultant decrease in the charge density and favorable change in conformation could have resulted in no aggregation.

3.6.3. Cytotoxicity of polymer. The cytotoxicity of LPEI and HELPEIs was determined in vitro in CFBE410- cells. The biocompatibility of any polymer is reported to be governed by polymer properties such as molecular weight, charge density and type of charge bearing functionality, structure (block, random, linear, and branched) and conformational flexibility. ${ }^{26}$ Different methods to reduce cytotoxicity are based on charge reduction and surface coating with hydrophilic polymer such as PEG. As shown in Fig. 4C, LPEI was found to be very toxic as it reduced the cell viability to $15 \%$ at $80 \mu \mathrm{g} \mathrm{mL} \mathrm{m}^{-1}$ and less than $55 \%$ at all the concentrations tested. This could be due to biphasic toxicity of PEI: first rapid phase (30 $\mathrm{min})$, due to translocation of phosphatidylserine from inside to outer cell surface; second delayed phase (24 h), due to channels formation in outer mitochondrial membrane and disturbance of membrane potential. ${ }^{30}$

In case of HELPEIs, it was observed that the cytotoxicity decreased with increase in DS. This was attributed to cumulative effect of decrease in the charge density at physiologic $\mathrm{pH}$ of 7.4, alteration in structural and conformational property, as well as increased hydrophilicity. At DS of $15 \%$ and $25 \%$ there was significant toxicity $(p<0.05)$. However, after further increase in DS, HELPEI-35 and HELPEI-45 showed significant improvement in cell viability, almost $\sim 90 \%$ and more at all concentrations, compared to other polymers $(p<0.05)$. Therefore, based on biocompatibility studies, HELPEI-35 and HELPEI-45 were concluded as desired safe vectors and were considered for further characterization.

Table 2 Particle size and zeta potential of LPEI and HELPEI polyplexes

\begin{tabular}{|c|c|c|c|c|}
\hline Formulation & $\mathrm{n} / \mathrm{p}$ ratio & Particle size (nm) & Mean PDI & Zeta potential $(\mathrm{mV})$ \\
\hline \multirow[t]{2}{*}{ LPEI } & 4 & $168.7 \pm 4.5$ & $0.219 \pm 0.013$ & $26.2 \pm 1.54$ \\
\hline & 6 & $129.8 \pm 2.3$ & $0.147 \pm 0.009$ & $29.4 \pm 1.61$ \\
\hline \multirow[t]{2}{*}{ HELPEI-15 } & 5 & $185.3 \pm 3.8$ & $0.215 \pm 0.018$ & $25.8 \pm 2.50$ \\
\hline & 7 & $135.2 \pm 3.2$ & $0.152 \pm 0.014$ & $28.1 \pm 1.68$ \\
\hline \multirow{2}{*}{ HELPEI-25 } & 6 & $213.5 \pm 4.6$ & $0.237 \pm 0.017$ & $24.1 \pm 1.84$ \\
\hline & 8 & $138.8 \pm 2.5$ & $0.171 \pm 0.012$ & $26.6 \pm 1.55$ \\
\hline \multirow[t]{2}{*}{ HELPEI-35 } & 8 & $248.9 \pm 4.7$ & $0.259 \pm 0.025$ & $18.3 \pm 2.79$ \\
\hline & 10 & $156.5 \pm 5.6$ & $0.175 \pm 0.015$ & $21.2 \pm 1.70$ \\
\hline \multirow[t]{2}{*}{ HELPEI-45 } & 15 & $311.2 \pm 6.2$ & $0.287 \pm 0.028$ & $17.3 \pm 2.81$ \\
\hline & 17 & $195.7 \pm 4.4$ & $0.213 \pm 0.019$ & $17.5 \pm 2.87$ \\
\hline
\end{tabular}


Table 3 Complexation efficiency at the optimized $n / p$ ratio

\begin{tabular}{lcc}
\hline Formulation & $\begin{array}{l}\text { Optimized } \mathrm{n} / \\
\text { p ratio }\end{array}$ & $\begin{array}{l}\text { Complexation } \\
\text { efficiency (\%) }\end{array}$ \\
\hline LPEI & 6 & $97.29 \pm 1.36$ \\
HELPEI-15 & 7 & $98.54 \pm 2.04$ \\
HELPEI-25 & 8 & $97.37 \pm 1.29$ \\
HELPEI-35 & 10 & $97.09 \pm 2.44$ \\
HELPEI-45 & 17 & $95.48 \pm 2.62$
\end{tabular}

\subsection{Stability challenge studies}

3.7.1. Electrolyte induced flocculation. LPEI showed a dramatic $\sim 1.8$-fold increase in size after salt additions (Fig. 5A). This indicates that stability of LPEI was largely governed by ionized functional groups and resultant balance between attractive and repulsive force i.e. a response similar to lyophobic colloid to salt addition. ${ }^{31}$ The counterions from salt neutralize opposite charges and induce particle aggregation. However, the HELPEI polyplexes retained size to a considerable extent. HELPEI-35 and HELPEI-45 showed only 1.19 and 1.17fold increase in initial size, respectively. HELPEI might have derived significant portion of its stability from the hydrated hydroxyethyl chains, rather than ionized functional groups. ${ }^{32}$ The response was similar to that of lyophilic colloids, which derive stability from hydrophilic substituents and are less sensitive to salt additions.

3.7.2. Resistance to heparin displacement. The resistance to heparin competition assay depends on ratio of heparin to siRNA. This also gives idea, whether the formulations were made at appropriate $\mathrm{n} / \mathrm{p}$ in context of in vivo stability. ${ }^{33}$ Stability up to heparin/siRNA weight ratio of $>1$ is considered appropriate for achieving adequate in vivo stability. ${ }^{34}$ Fig. 6, shows that LPEI polyplex showed displacement from weight ratio of 2 , and finally $100 \%$ dissociated at heparin/siRNA weight ratio of 4 . The HELPEI-35 and HELPEI-45 polyplexes were evaluated at their optimized $\mathrm{n} / \mathrm{p}$ ratio. It was found that HELPEI-35 started releasing siRNA from heparin/siRNA weight ratio of 1.5 and completely released at weight ratio of 3 . HELPEI45 started releasing siRNA from heparin to siRNA weight ratio of 1.0 and completely released at weight ratio of 2 . Thus, HELPEI35 polyplexes had higher resistance than HELPEI-45 polyplexes.

3.7.3. Serum stability study. The serum stability is essential, since polyions present in the extracellular matrix in vivo and in vitro cell culture media can compete with siRNA and displace them. ${ }^{35}$ LPEI polyplexes showed good stability in serum challenge study. The HELPEI-35 polyplexes showed excellent stability which was evidenced as absence of degraded siRNA in gel electrophoresis. The band of the siRNA released after heparin treatment of samples had $>96 \%$ siRNA, while HELPEI45 had $>80 \%$ of siRNA at all-time points. On the other hand, naked siRNA showed degradation in $6 \mathrm{~h}$ (Fig. 6D-F).

\subsection{TEM}

Fig. 5B shows the morphology of the HELPEI-35 and HELPEI-45 polyplexes as observed through TEM. The TEM images showed that polyplexes were spherical and compact. They were discrete with no visible evidence of aggregation, proving the homogenous state of system. The images support the light scattering data; however, the size was relatively smaller than that observed in DLS measurement. The effect might be result of recording of hydrodynamic radius of the particles in DLS which is more than the actual size.


B)

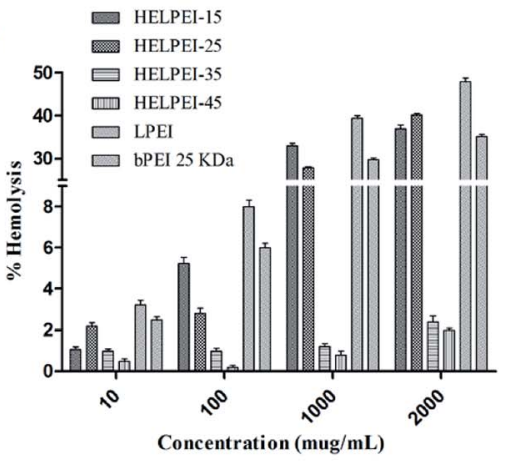

C)
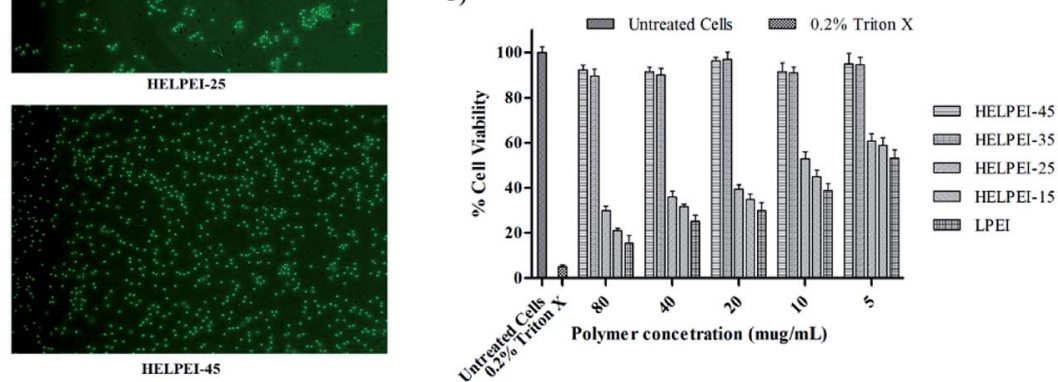

Fig. 4 (A) Results of erythrocyte aggregation study; (B) hemolytic potential of different HELPEls at different concentrations; (C) cytotoxic potential of polymers at different concentrations. 
A

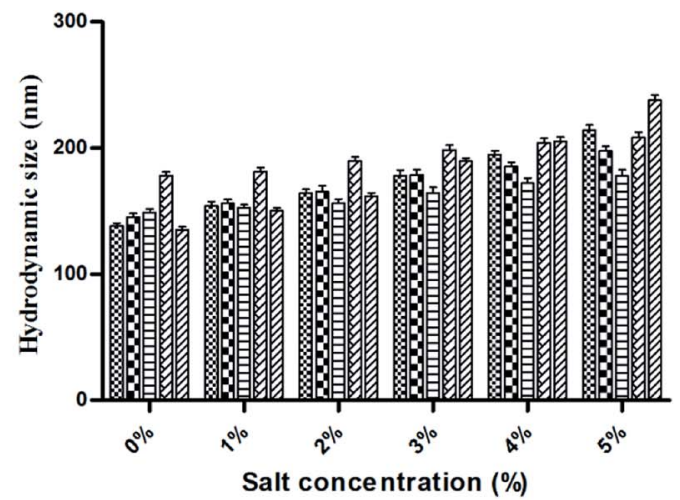

\% HELPEI-15

W.7. HELPEI-25

Е HELPEI-35

HELPEI-45

एखय LEPI
B)

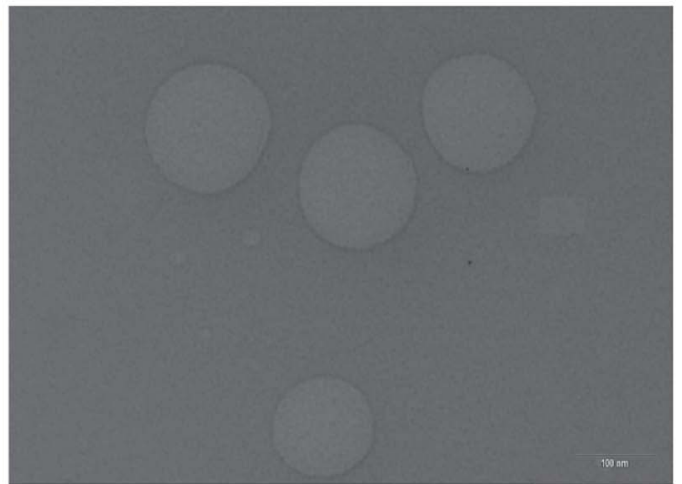

C)

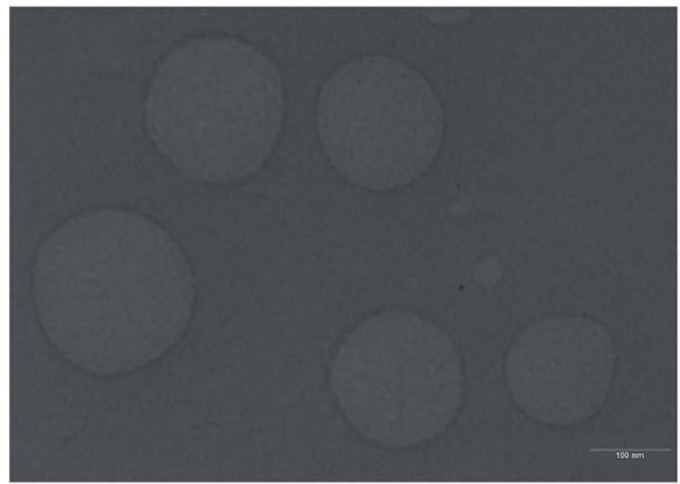

Fig. 5 (A) Electrolyte induced flocculation. (B) TEM image of HELPEI-35 polyplex; (C) TEM image of HELPEI-45 polyplex.

\subsection{Cell uptake}

3.9.1. Confocal microscopy. As seen from Fig. 7, naked siRNA showed negligible cellular uptake, while PEI polyplexes showed marked cellular uptake. The observed low uptake of naked siRNA is direct result of high molecular weight as well as high hydrophilicity which interferes with membrane interaction and cell uptake. The commercial transfecting agent, L2K showed significant cell uptake. $\begin{array}{lllllllll}\text { Lane no. } & 1 & 2 & 3 & 4 & 5 & 6 & 7 & 8\end{array}$

A)

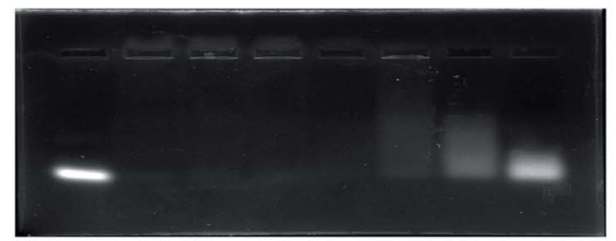

B)

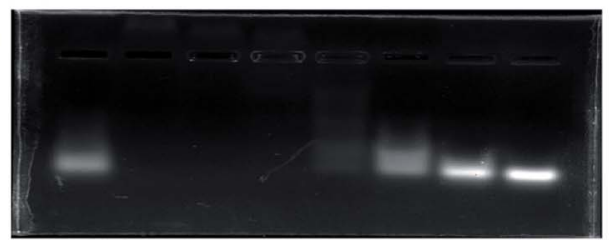

C)

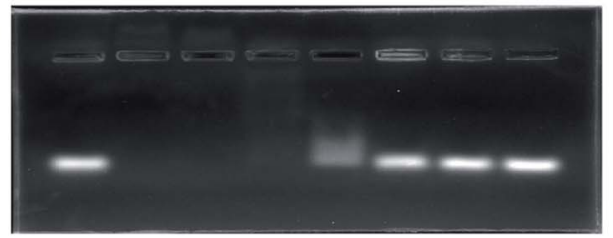

D)

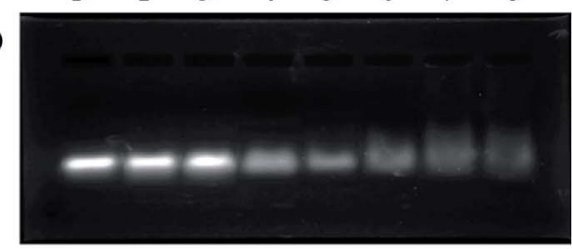

E)

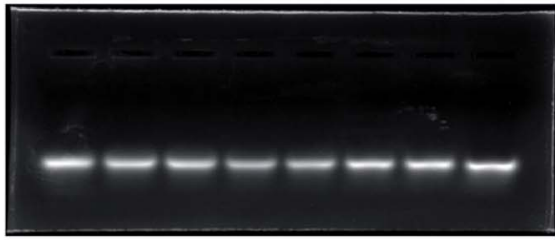

F)

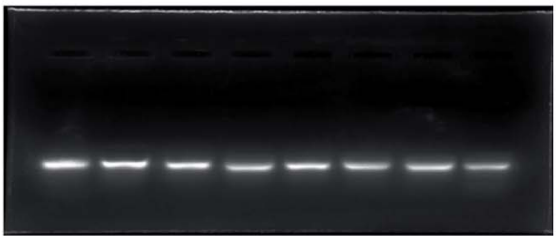

Fig. 6 (A-C) Resistance to heparin displacement assay of polyplexes of (A) LPEl; (B) HELPEI-35; (C) HELPEI-45 heparin/siRNA w/w ratio: lane1: naked siRNA, lane 2: 0.25, lane 3: 0.5, lane 4: 1.0, lane 5: 1.5, lane 6: 2, lane 7: 3, lane 8: 4). (D-F) Serum stability study showing siRNA released at time points: $(D)$ naked siRNA at time lane $1=0 \mathrm{~h}$, lane $2=0.5 \mathrm{~h}$, lane $3=1.0 \mathrm{~h}$, lane $4=2.0 \mathrm{~h}$, lane $5=3.0 \mathrm{~h}$, lane $6=4.0 \mathrm{~h}$, lane $7=5.0 \mathrm{~h}$, lane $8=$ $6.0 \mathrm{~h}$; (E and F) HELPEI-35 and HELPEI- 65 respectively at times: lane $1=0 \mathrm{~h}$, lane $2=1.0 \mathrm{~h}$, lane $3=2.0 \mathrm{~h}$, lane $4=4.0 \mathrm{~h}$, lane $5=8.0 \mathrm{~h}$, lane $6=$ $16 \mathrm{~h}$, lane $7=24 \mathrm{~h}$. 
A)
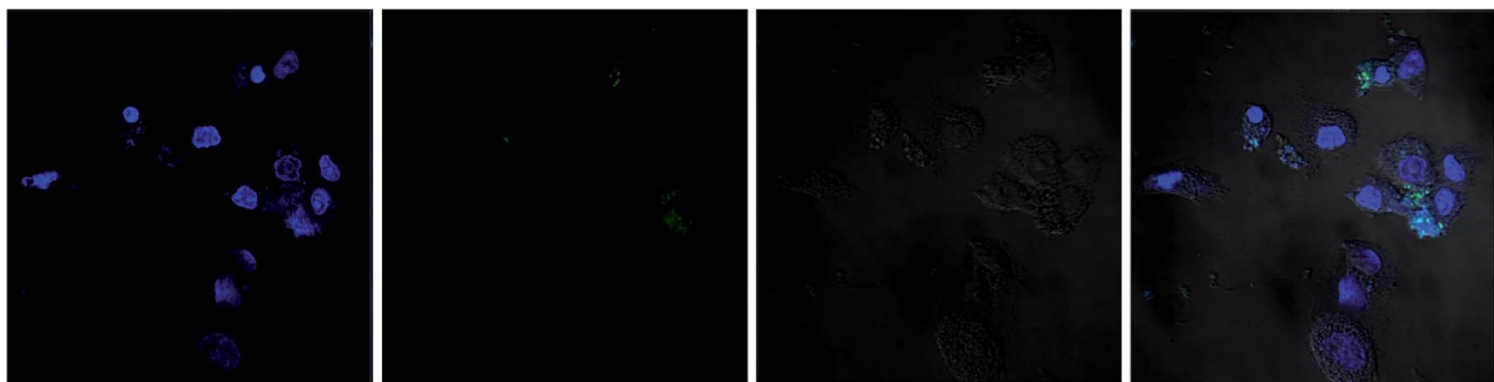

B)
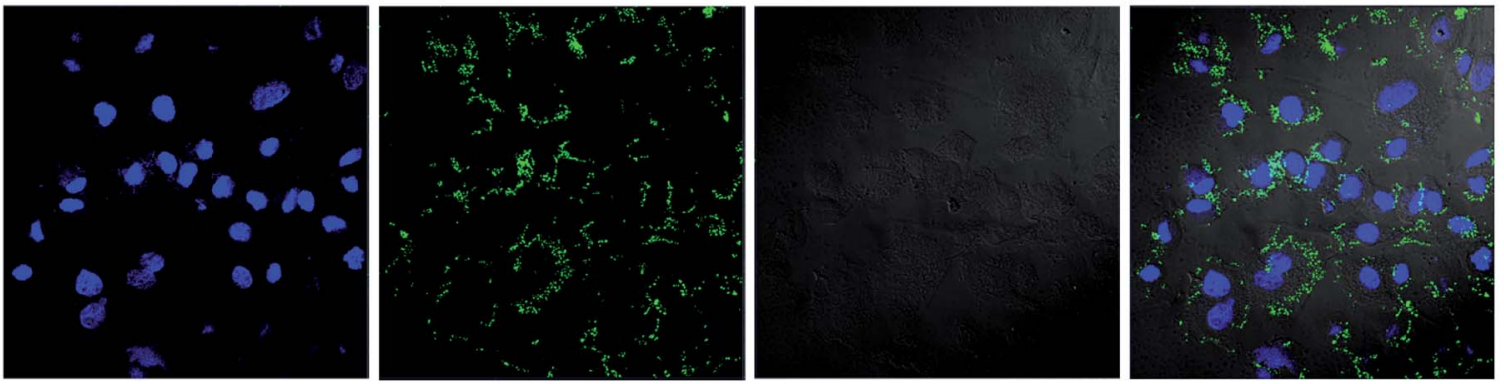

C)
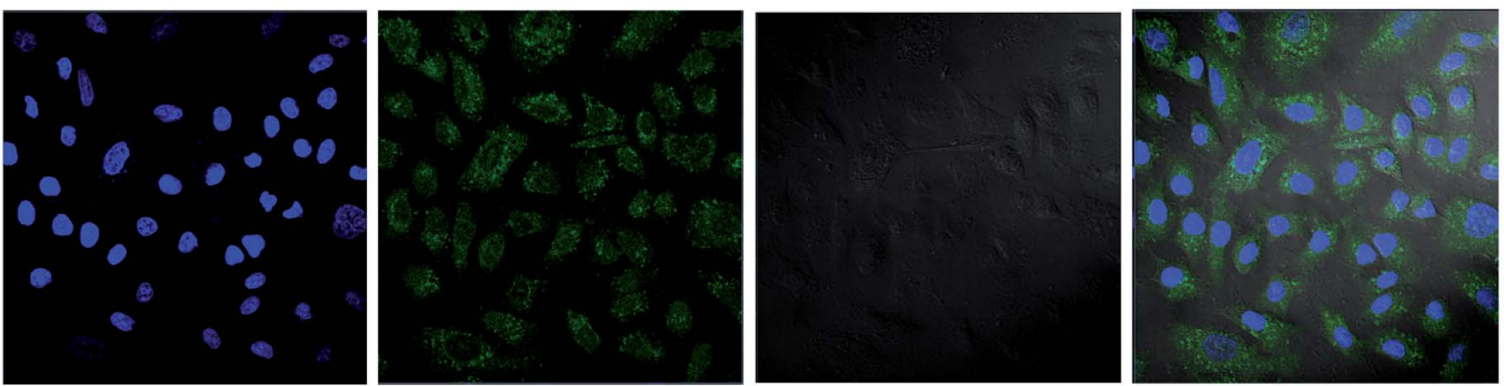

D)
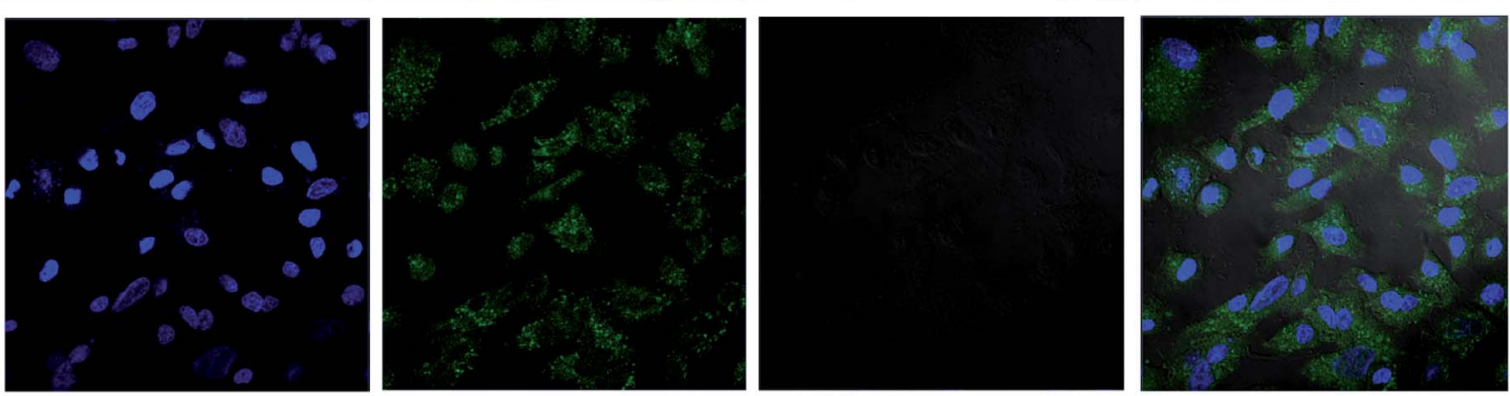

E)
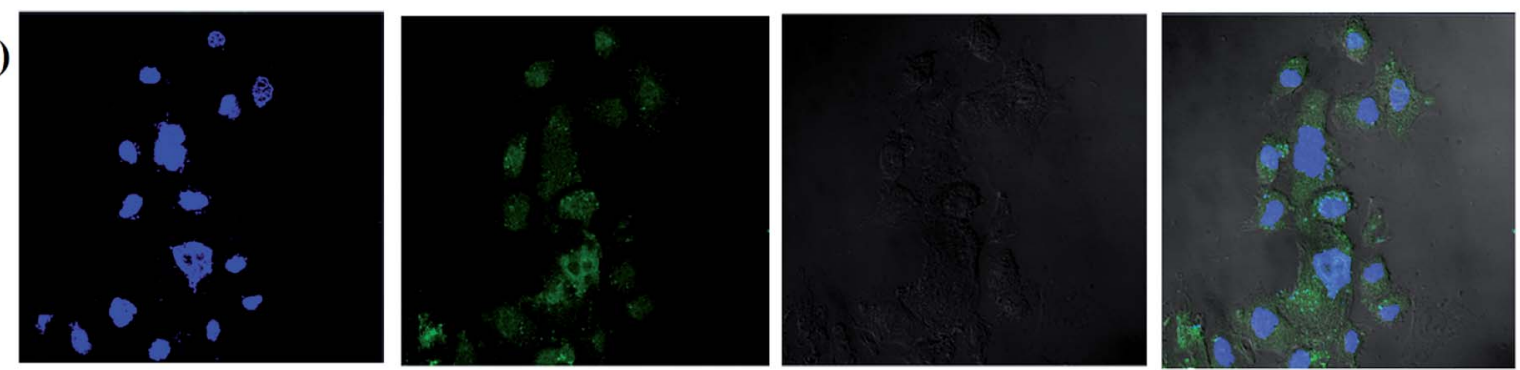

Fig.7 Cell uptake of screened formulations by confocal microscopy; (A) naked siRNA, (B) LPEl polyplexes, (C) HELPEI-35 polyplexes, (D) HELPEI45 polyplexes, (E) L2K lipoplexes.

On the other hand, LPEI, being cationic charged, forms polyplexes with siRNA and protects it from degradation. However, LPEIs association with the cells had a typical pattern, in which fluorescence was observed around cell membrane high-lighting the periphery of cell. The literature reports also show similar observations in case of LPEI. ${ }^{23,36}$ In contrast, polyplexes of HELPEI-35 and HELPEI-45 showed considerable uptake compared to naked siRNA. The fluorescence was throughout the cytoplasm rather than at the cell periphery, which indicates good cytoplasmic intake of siRNA. Literature reports that, PEGylated carriers interfere with cell interaction due to presence of large hydration shell leading to lower cell 
uptake. ${ }^{37}$ However, the small length hydrophilic groups used in present case did not interfere with cell surface interaction.

3.9.2. FACS. It was apparent from the data, Fig. 8, that cells treated with naked FAM-NC-siRNA showed very low level of uptake ( $\sim 9.0 \%)$, while PEI based positively charged polyplexes and Lipofectamine showed higher uptake (>60\%) inside cells. Similarly, LPEI and HELPEI polyplexes showed significant cell uptake compared to naked siRNA $(p<0.05)$. The LPEI polyplexes, due to cationic charge and small size are able to show significant cell association. The increase in DS suppressed the cationic charge in HELPEIs polyplexes; however, the residual cationic charge was sufficient to encourage membrane interaction and allow endocytosis. However, the difference in cell uptake of HEPEIs and LPEI was significant $(p<0.05)$. The lower cell uptake in case of LPEI could be attributed to the cytotoxicity, aggregation of particles.

Comparison of HEPEI-35 and HELPEI-45 polyplexes showed that cell uptake in case of HELPEI-35 was higher than that of
HELPEI-45 $(p<0.05)$. This means that increased DS beyond certain point does not lead to increase in cell uptake, which may be due to poor cell interaction as a result of significant suppression of ionization. The developed biocompatible HELPEI-35 and HELPEI-45 showed a significant improvement $(p<0.05)$ in cell uptake compared to LPEI. Thus, based on FACS data the order of cell uptake of analyzed formulations could be stated as: HELPEI-35 > HEPEI-45 > L2K > LPEI > naked siRNA.

\subsection{RT-PCR}

To study the gene knockdown real time PCR was used. The cells were transfected with siRNA concentration at $25 \mathrm{nM}, 50 \mathrm{nM}$ and $100 \mathrm{nM}$. To confirm that gene silencing was due to siRNA only and not due to any off-target effect or non-specific inhibitions, we also included polyplexes of HELPEI-35-NC-siRNA, which showed negligible gene knockdown compared to the control. As shown in Fig. 9, highest knockdown was observed at $100 \mathrm{nM}$
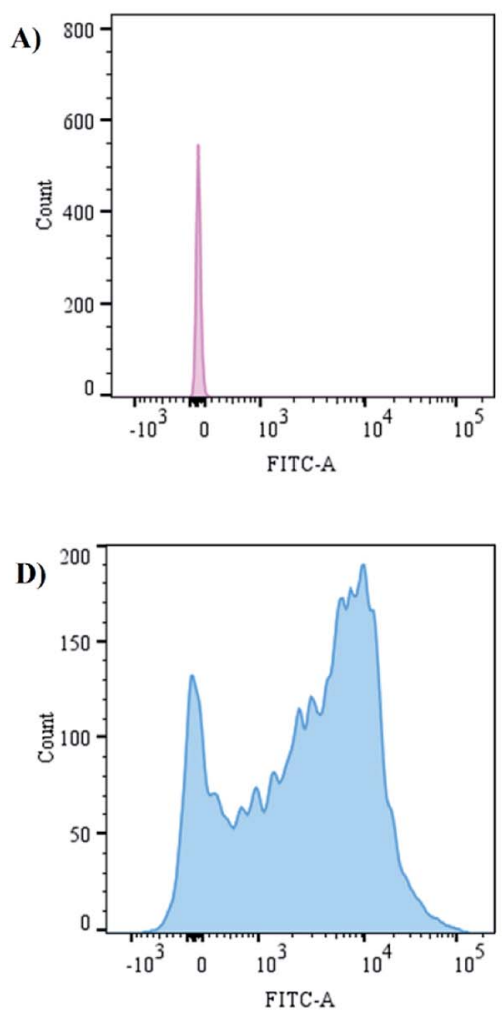
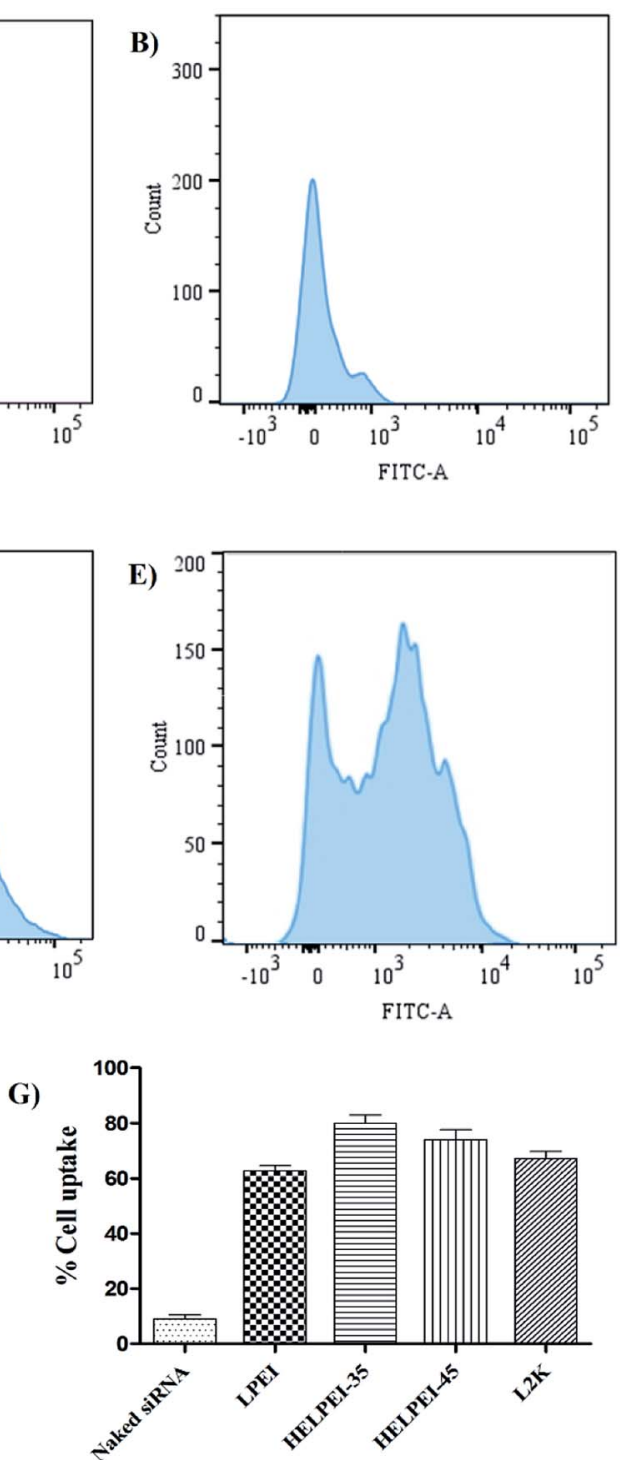
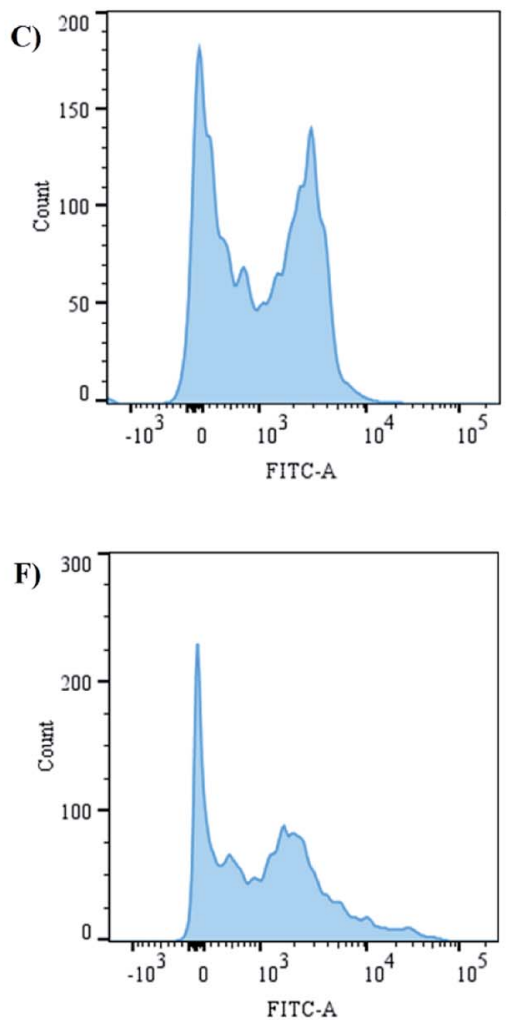

Fig. 8 Histograms of FACS analysis, (A) unstained control, (B) naked siRNA, (C) LPEI polyplexes, (D) HELPEI-35 polyplexes, (E) HELPEI-45 polyplexes, (F) L2K lipoplexes and (G) \% cell uptake observed in FACS. 


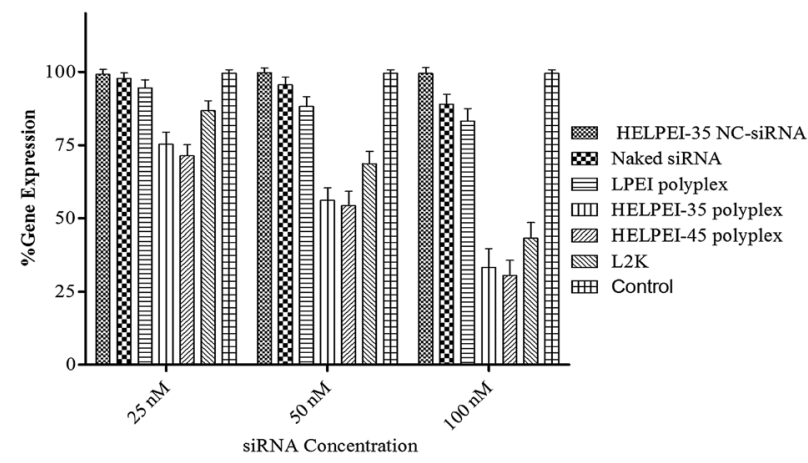

Fig. $9 \%$ gene expression in CFBE410- cells after treatment LPEI based formulations.

siRNA. At this level, naked siRNA showed $89.03 \pm 3.38 \%$ gene expression. At the same concentration HELPEI-35 and HELPEI45 polyplexes showed $33.32 \pm 6.39 \%$ and $30.54 \pm 5.14 \%$ gene expression, respectively, which was significantly higher than LPEI. Lipofectamine (L2K), also showed good transfection efficiency $(43.34 \pm 5.16 \%)$.

Although FACS studies had shown good cell uptake for LPEI, the transfection was not in concordance with it. This can be explained by confocal studies which showed that cellular association of LPEI was preferentially on the membrane with little cytoplasmic appearance. It might be possible that surface associated polyplex were not internalized or unable to escape from endosomes after internalization. Thus, positive surface character may ensure cell attachment, the subsequent endosomal escape and unloading is a limiting factor in gene expression. Similarly, cationic polymers such as poly-L-lysine, poly arginine etc. are less efficient in transfection because of their poor endosomal escape capacity. ${ }^{38}$

The endosomal escape is essential, otherwise the nucleic acid is readily degraded following drop in $\mathrm{pH}$ in endosomallysosomal pathway. The superiority of HELPEIs over LPEI could be attributed to higher buffer capacity (Table 1) and greater cytoplasmic uptake as observed in confocal images. Further, though HELPEI-35 and HELPEI-45 polymer were equivalent in buffer capacity, the difference in gene expression between HELPEI-35 and HELPEI-45 polyplexes can be explained based on results of FACS, which showed that, HELPEI-35 polyplexes were more efficient in cell uptake due to greater positive surface charge than HELPEI-45 polyplexes.

\section{Conclusion}

The study demonstrates the beneficial effect of proposed modification of LPEI on the physicochemical and biological properties of LPEI. Compared to other PEI modification, which require tedious and multistep synthesis, the present study provides a simple alternative. The results showed that hydroxyethyl substitution improved the hydration properties, solubility of LPEI. Further, it changed the ionization behavior due to conversion of secondary amines into tertiary amines and nextnearest-neighbor interactions leading to suppression of ionization. The suppressed ionization led to decreased surface charge at physiologic $\mathrm{pH}$ along with a possible change in conformational flexibility leading to reduced hemolytic potential and cytotoxicity. The study also showed that with proper choice of DS, the suppression of ionization can be influenced in way so as to benefit the most important aspect of nucleic acid delivery i.e. proton sponge capacity and endosomal escape. Finally, cell uptake and transfection behavior demonstrated the potential for safe and efficacious delivery of siRNA.

\section{Conflicts of interest}

There are no conflicts to declare.

\section{Acknowledgements}

We are grateful to financial support from University Grant Commission (UGC), INDIA, in the form of fellowship. Authors are also thankful to Vikram Sarabhai central instrumentation facility, Maharaja Sayajirao University of Baroda for confocal and FACS studies.

\section{References}

1 N. Schütze, Mol. Cell. Endocrinol., 2004, 213, 115-119.

2 K. A. Whitehead, R. Langer and D. G. Anderson, Nat. Rev. Drug Discovery, 2009, 8, 129-138.

3 H. Y. Xue, S. Liu and H. L. Wong, Nanomedicine, 2014, 9, 295312.

4 C. I. Contescu, K. Putyera and J. A. Schwarz, Dekker Encyclopedia of Nanoscience and Nanotechnology, CRC Press Taylor \& Francis Group, 2009, vol. 1.

5 Y. W. Cho, J. D. Kim and K. Park, J. Pharm. Pharmacol., 2003, 55, 721-734.

6 R. Goyal, S. K. Tripathi, S. Tyagi, A. Sharma, K. R. Ram, D. K. Chowdhuri, Y. Shukla, P. Kumar and K. C. Gupta, Nanomedicine: Nanotechnology, Biology and Medicine, 2012, 8, 167-175.

7 J. Suh, H.-j. Paik and B. K. Hwang, Bioorg. Chem., 1994, 22, 318-327.

8 J. D. Ziebarth and Y. Wang, Biomacromolecules, 2010, 11, 2938.

9 A. Kichler, M. Chillon, C. Leborgne, O. Danos and B. t. Frisch, J. Controlled Release, 2002, 81, 379-388.

10 P. Banerjee, R. Weissleder and A. Bogdanov, Bioconjugate Chem., 2006, 17, 125-131.

11 J. H. Jeong, S. H. Song, D. W. Lim, H. Lee and T. G. Park, J. Controlled Release, 2001, 73, 391-399.

12 J. Dai, S. Zou, Y. Pei, D. Cheng, H. Ai and X. Shuai, Biomaterials, 2011, 32, 1694-1705.

13 H. Koo, G.-w. Jin, H. Kang, Y. Lee, K. Nam, C. Z. Bai and J.-S. Park, Biomaterials, 2010, 31, 988-997.

14 A. von Harpe, H. Petersen, Y. Li and T. Kissel, J. Controlled Release, 2000, 69, 309-322.

15 C. Lin and J. F. Engbersen, Mater. Sci. Eng., Proc. Conf., 2011, 31, 1330-1337.

16 H. A. Liu, Y. L. Liu, Z. Z. Ma, J. C. Wang and Q. Zhang, Invest. Ophthalmol. Visual Sci., 2011, 52, 4789-4794. 
17 H. Katas and H. O. Alpar, J. Controlled Release, 2006, 115, 216-225.

18 L. Aravindan, K. A. Bicknell, G. Brooks, V. V. Khutoryanskiy and A. C. Williams, Int. J. Pharm., 2009, 378, 201-210.

19 P. Bhatt, R. Lalani, I. Vhora, S. Patil, J. Amrutiya, A. Misra and R. Mashru, Int. J. Pharm., 2018, 536, 95-107.

20 A. Kolate, G. Kore, P. Lesimple, D. Baradia, S. Patil, J. W. Hanrahan and A. Misra, J. Microencapsulation, 2014, 1-14.

21 K. Singarapu, I. Pal and J. D. Ramsey, J. Biomed. Mater. Res., Part A, 2013, 101, 1857-1864.

22 R. Smits, G. Koper and M. Mandel, J. Phys. Chem., 1993, 97, 5745-5751.

23 F. W. Huang, H. Y. Wang, C. Li, H. F. Wang, Y. X. Sun, J. Feng, X. Z. Zhang and R. X. Zhuo, Acta Biomater., 2010, 6, 4285-4295.

24 G. P. Tang, J. M. Zeng, S. J. Gao, Y. X. Ma, L. Shi, Y. Li, H. P. Too and S. Wang, Biomaterials, 2003, 24, 2351-2362.

25 S. Patil, P. Bhatt, R. Lalani, J. Amrutiya, I. Vhora, A. Kolte and A. Misra, RSC Adv., 2016, 6, 110951-110963.

26 D. Fischer, Y. Li, B. Ahlemeyer, J. Krieglstein and T. Kissel, Biomaterials, 2003, 24, 1121-1131.

27 A. M. Doody, J. N. Korley, K. P. Dang, P. N. Zawaneh and D. Putnam, J. Controlled Release, 2006, 116, 227-237.
28 I. Sovadinova, E. F. Palermo, R. Huang, L. M. Thoma and K. Kuroda, Biomacromolecules, 2011, 12, 260-268.

29 T. L. Fabry, Blood, 1987, 70, 1572-1576.

30 S. M. Moghimi, P. Symonds, J. C. Murray, A. C. Hunter, G. Debska and A. Szewczyk, Mol. Ther., 2005, 11, 990-995.

31 E. Verwey, Chem. Rev., 1935, 16, 363-415.

32 S. N. Siegman, 2014.

33 P. Vader, L. J. van der Aa, J. F. Engbersen, G. Storm and R. M. Schiffelers, Pharm. Res., 2012, 29, 352-361.

34 A. A. Foster, C. T. Greco, M. D. Green, T. H. Epps 3rd and M. O. Sullivan, Adv. Healthcare Mater., 2015, 4, 760-770.

35 C. Troiber, D. Edinger, P. Kos, L. Schreiner, R. Klager, A. Herrmann and E. Wagner, Biomaterials, 2013, 34, 16241633.

36 L. Wightman, R. Kircheis, V. Rossler, S. Carotta, R. Ruzicka, M. Kursa and E. Wagner, J. Gene Med., 2001, 3, 362-372.

37 S. Fuxin, L. Wasungu, A. Nomden, M. C. Stuart, E. Polushkin, J. B. Engberts and D. Hoekstra, Biochem. J., 2002, 366, 333341.

38 W. Liang and J. K. Lam, Endosomal escape pathways for nonviral nucleic acid delivery systems, INTECH Open Access Publisher, 2012. 